\section{Ethics and necropsies}

Other people's views on one's profession are often revealing, and Professor DN Baron's recent leading article about the ethical duties of pathologists was especially illuminating. ${ }^{1}$ His list of those towards whom we have such responsibilities was very interesting, though, as a pathologist interested in publicising the benefits of the necropsy, I was surprised that patients' families were not included in the list.

Professor Baron's classification of our duties towards others can, in fact, be applied neatly to necropsy practice. For instance, there is clearly potential and actual conflict between the need for nonmaleficence towards relatives, who might be dismayed by a necropsy, and our duty of beneficence towards our clinical colleagues and the general public, who gain from the audit and educational aspects of the necropsy. The continuing fall in necropsy rates $^{2}$ could be ascribed to a progressive change in the relative importance awarded to these two principles. Estimates of maleficence and beneficence are clearly subjective, and some would argue that some clinicians exaggerate the maleficence of the necropsy towards relatives. ${ }^{3}$

The quest for justice, another duty quoted by Professor Baron, may also conflict with other ethical duties. One obvious example is that the value of Coroners' necropsies to clinicians and others may be reduced by strict adherence to medicolegal constraints. ${ }^{45}$ Even the duty to consider the patient's autonomy needs to be considered by some pathologists, such as those involved in research programmes in which permission for eventual removal of the brain is sought before death. ${ }^{6}$

Any amateur philosopher could expand on this list of principles; perhaps Professor Baron could be persuaded to provide a professional analysis.

EW BENBOW Pological Sciences, Oxford Road, Manchester, M13 9PT

1 Baron DN. Ethical issues and clinical pathology. I Clin Pathol 1993;46:385-7.

2 Start RD, McCulloch TA, Benbow EW, Lauder I, Underwood JCE. Clinical necropsy rates during the 1980 s: the continued decline. $\mathcal{F}$ Pathol (in press)

3 McPhee SJ, Bottles K, Lo B, Saika G, Crommie D. To redeem them from death. Reactions of family members to autopsy. Reactions of family memb

4 Leadbeatter S, Knight B. Reporting deaths to coroners. BMF 1993;306:1018.

5 Benbow EW. Relative friendly death certificates. F Clin Pathol 1993;46:782.

6 Murphy E, Procter A. Brains for biochemical research. Int $\mathcal{f}$ Geriatr Psychiatry 1990;5: 281-2.

\section{Professor Baron comments}

My leading article dealt with problems related to patient care. As Dr Benbow rightly points out a full discussion of the ethical (and legal) responsibilities of pathologists must incorporate those related to necropsies, which includes responsibilities to patients' families. A further example of the way that problems of pathologists are ignored in medical ethics generally is found in an excellent discussion in a new textbook of the relation of persons to bodies, and our consequent thoughts and actions, which does not even mention the necropsy. ${ }^{1}$

The ethical responsibilities of histopathologists in respect to necropsies which cannot be dissociated from the legal duties,
I believe, lie in three stages: (1) before; (2) during; (3) after.

(1) We accept that performing necropsies has a beneficent effect towards clinicians, other pathologists, and the public as future patients by acting as an audit ${ }^{2}$ and improving our knowledge of disease, to be balanced against non-maleficence to relatives who may be distressed by the proposal, or even to a few clinicians who may not like their diagnoses to be shown as wrong. I believe that it would be unethical, because of adding to the strain on the relatives, for the pathologist (who has almost certainly not previously met them nor the patient) to interview them and ask consent-though this has been reported. ${ }^{3}$ It is the obligation of pathologists however, to encourage the performance of necropsies by influencing clinicians as to their general importance. ${ }^{4}$ In addition, where a pathologist knows that in a particular case there has been a major diagnostic problem, or the possibility of grave therapeutic misadventure, he has to stimulate the responsible clinical staff to make the request for consent. If there is no response then in serious cases he may be justified in taking further the need for a necropsy, by reporting to the coroner, ${ }^{5}$ the ethical imperative being beneficence to society in reducing medical error.

(2) Most societies believe that a body commands respect, at least as a reminder of the person that it once was. ${ }^{16}$ Discussion of this major topic, and its relation to necropsies, is outside the scope of this letter; in some societies, for example, a body has to be buried without interference. The ethical obligation not to mutilate the body does not therefore depend only on the obligation not to distress the relatives. A particular instance of such non-maleficence is that the parts of the body subsequently seen by the relatives, primarily face and hands, should not be altered without informing them of the need. No distinction may be made between the care owed to living and to dead patients: for example, pathologists have a duty to perform necropsies on HIV positive patients if required, provided that management have done their duty in providing appropriate facilities and assistance. ${ }^{7}$ Before starting the necropsy the pathologist must check that consent has been formally granted by the next of kin or executor, and whether any restrictions have been placed on the extent of the necropsy. Specific permission is needed for tissue to be removed for research; and the consent form can include a section agreeing to this ${ }^{2}$; judges might adopt the view that unauthorised action amounted to a common law offence of unlawful interference with a corpse. ${ }^{8}$ An American case yielded US\$150000 in damages for distress to a widow whose husband's brain had been removed at necropsy without permission. ${ }^{9}$

(3) The obligation to inform the relatives of the result of the necropsy rests with the clinician, to whom has been sent the pathologist's report and which they now have a legal right to read: it would be unethical for the report to be sent directly to the relatives because they may need elucidation and counselling by the person who has cared for the patient. If, however, either the clinician asks the pathologist to send the relatives a copy of the report, or requests that he joins in the discussion with the relatives, or the relatives contact the pathologist directly for an explanation, it would be a beneficent act to help-in the latter case the clinician should be told of the discussion.

Dr Benbow mentions the obligation of justice. In the current context this applies to the problems that histopathologists, as all pathologists, have in balancing the demands on the resources available to their departments. The more resources that are put into necropsies the less are available for other purposes, which emphasises the need to establish their worth. ${ }^{3}$

1 Campbell A, Gillett G, Jones G. Practical medical ethics. Auckland: Oxford University medical ethics. Auc.

2 Report of Joint Working Party. The autopsy and audit. London: The Royal College of Pathologists, 1991

3 McPhee SJ, Bottles K, Lo B, Saika G, Crommie D. To redeem them from death. Reactions of family members to autopsy. Am $\mathcal{F}$ Med 1986;80:665-71.

4 Champ C, Tyler X, Andrews PS, Coghill SB. Improve your hospital autopsy rate to $40-50$ per cent, a tale of two towns. F Pathol 1992; 166:405-7.

5 Knight B. Legal aspects of medical practice. Edinburgh: Churchill Livingstone, 1992: 93-108.

6 Iserson KV. Postmortem procedures in the emergency department: using the recently dead to practise and teach. $\mathcal{F}$ Med Ethics 1993;19:92-8.

Ratzan RM, Scheidermann H. AIDS, autopsies, and abandonment. $\mathcal{F} A M A \quad 1988 ; 260$ : 3466-9.

8 Skegg PDG. Criminal liability for the unauthorized use of corpses for medica 32:51-4.

9 Meyers DW. The human body and the law. 2nd edn. Edinburgh: Edinburgh University Press, 1990:189.

Value of face masks at post mortem examination

There have been many studies performed and letters written regarding the risk of transmission of infectious diseases by being splashed with body fluids. These risks have been particularly recognised by orthopaedic and maxillofacial surgeons due to their use of power tools. ${ }^{12}$ Both the Howie code ${ }^{3}$ and the Advisory Committee on Dangerous Pathogens $^{4}$ state that full face protection should be worn in known infectious cases at post mortem examination. In our experience this is rarely done in routine cases as full face visors are uncomfortable to wear and may obscure vision.

Bull et $a l^{5}$ have shown the need for eye protection at post mortem examination, but to our knowledge, the risk from contact with the nasal and oral mucosae and the skin of the face (which may be broken) has not been studied. Contamination through contact of infected blood with oral mucosa and inapparent skin lesions has been reported. ${ }^{6}$ Although this route may rarely result in transmission of infectious diseases, the increasing prevalence of HIV increases the potential for such exposures. The magnitude of the risk is not known as there are no data on the frequency with which exposure of contaminated blood with skin, oral, and nasal mucosae occurs.

Fifty necropsies were performed on adults by three junior pathologists wearing standard surgical face masks, one during evisceration and one for dissection of the organs. At the end of each procedure, the number of splashes on the external surface of each mask were counted with the aid of a hand lens. Power tools were not used.

Overall, splashes occurred during either evisceration, organ dissection, or both, in 20 out of the $50(40 \%)$ cases. In nine out of 